\title{
Fundamental Consideration for Electrochemical Engineering of Supercapattery
}

\author{
Bamidele Akinwolemiwa ${ }^{a, b}$ and George Z. Chen ${ }^{*, a, c}$ \\ ${ }^{a}$ Energy Engineering Research Group, Department of Chemical and Environmental Engineering, \\ Faculty of Science and Engineering and ${ }^{b}$ International Doctoral Innovation Centre, \\ University of Nottingham Ningbo China, 315100 Ningbo, China \\ ${ }^{c}$ Advanced Materials Research Group, Department of Chemical and Environmental Engineering, \\ Faculty of Engineering, University of Nottingham, NG7 2RD, Nottingham, UK
}

\begin{abstract}
Supercapattery is the generic name for various electrochemical energy storage (EES) devices combining the merits of battery (high energy density) and supercapacitor (high power density and long cycling life). In this article, the principle and applications of EES devices are selectively reviewed as the background for supercapattery development. The focus is on the engineering aspects for fabrication of two types of supercapattery: $(i)$ by coupling a battery electrode with a supercapacitor electrode, or (ii) from materials that possess both the Nernstian and capacitive charge storage capacities. Fundamental rationales are discussed in relation with the designs, such as why the device is always asymmetrical, and what materials are suitable for making supercapattery. Whilst the key is how to optimize device performance in terms of energy capacity, power capability and cycle life, cost is also discussed on resource rich materials such as nanostructured composites and redox electrolytes.
\end{abstract}

Keywords: supercapattery, supercapacitor, battery, device engineering, redox materials

\section{Introduction}

The search for electrochemical energy storage (EES) technologies with high energy and power density, long cycle life and good commercial affordability has been the focus of laboratory research and commercial development in recent years. ${ }^{1-3}$ In line with this ongoing global effort, various hybrid devices of rechargeable battery and supercapacitor are becoming a particular interest of many researchers around the world ${ }^{3-10}$ Although having the same or similar research objectives and methodology, i.e., combination of the technical merits of supercapacitor (high power density and long cycle life) and rechargeable battery (high energy density), the current literature lacks clearly a generic and logical term for these hybrid devices. Very different names have been used, such as "redox capacitor", "pseudocapacitor", "Li-ion capacitor", "Na-ion capacitor", "hybrid electrochemical capacitor" and "hybrid supercapacitor". ${ }^{5-10}$ However, there is a particular concern on the latter four hybrid devices which are, strictly speaking, no longer capacitor or supercapacitor because their charge storage mechanisms are partly the same as that in a

*e-mail: george.chen@nottingham.ac.uk

This paper is part of the PubliSBQ Special Issue "IUPAC-2017" (http://publi.sbq.org.br/). rechargeable battery. This situation in the current literature is not helpful to focus the diverse research interests on materials designs, synthesis and characterizations. It may also confuse the fundamental understanding and commercial development of the respective products with those true supercapacitors.

Since 2008, the author and co-workers have proposed and promoted the use of a generic term, supercapattery (= supercapacitor + battery), to describe various hybrid EES devices that combine the merits of both supercapacitor and rechargeable battery. ${ }^{4,11-13}$ Firstly, a supercapattery with improved technical performance can basically be made from pairing and matching a battery electrode with a supercapacitor electrode. Secondly, it can be achieved alternatively by the combination of the supercapacitor and battery merits into a composite or uniquely structured material for making a new high performance electrode which is then used in making the supercapattery. In comparison with other terminologies for hybrid EES devices, supercapattery can provide a common conceptual basis for analysis, comparison and communication. It is acknowledged that as a new term, supercapattery is slowly but steadily gaining recognition of the EES community. ${ }^{11-28}$ In this regard, it is worth highlighting that both the Li-ion and Na-ion capacitors refer specifically to devices that 
would use Li-ion or Na-ion as the charge carrier in the cell, wherein one of the electrodes is a battery electrode on which Faradaic (but non-capacitive) charge storage occurs, and the other is a supercapacitor electrode on which charge storage is capacitive in mechanism. However, similar to "rechargeable battery" as a generic term for all batteries that are rechargeable, supercapattery is also a generic term and describes all devices using a battery electrode and a capacitive electrode in combination, including both the Li-ion and $\mathrm{Na}$ ion capacitors, and many other EES devices that utilize both capacitive and Faradaic charge storage mechanisms. ${ }^{2,3,17}$

Whilst a comprehensive review on supercapattery was published very recently, ${ }^{3}$ this article offers a concise and critical account of the past and ongoing research efforts of the author and co-workers in relation to the engineering fundamentals and development of supercapattery. It firstly briefs the basics of EES in general and supercapattery in particular from the angles of concepts, materials, devices and past research findings. The main focus then follows on the design principle and device engineering of supercapattery in terms of both theoretical analysis and practical demonstration according to the selected examples from relevant literature.

\section{The Concept of Supercapattery in the Context of EES Devices}

\subsection{Key components in EES devices}

All EES devices are composed of at least a positive electrode, a negative electrode and an electrolyte. Electrodes enable charge storage via either charge transfer reactions or accumulation of charges in the electrical double layers at the interface between the electrode and electrolyte. Either way, the current flow resulting from charge storage in the EES device is enabled by electron conduction in the electrode and ion transport in the electrolyte.

There are three types of electrode that have been in use in EES devices. Firstly, each of the two electrodes can be simply an electronic conductor which is electrochemically and chemically inert in the range of working potentials. A typical example is the activated carbon electrode in the first generation supercapacitor, i.e., the electric double layer capacitor (EDLC). The second type of electrode is exemplified by an active metal electrode, such as the lead $(\mathrm{Pb})$ metal negative electrode in the lead-acid rechargeable battery, and the zinc ( $\mathrm{Zn}$ ) metal negative electrode in the alkaline zinc-manganese dioxide rechargeable battery. There is also ongoing effort to directly use lithium $(\mathrm{Li})$ metal and aluminium $(\mathrm{Al})$ metal electrodes to make rechargeable battery with higher energy capacity (note that the lithium metal has long been used as the negative electrode in primary battery, but not yet in rechargeable battery for commercial purposes). It is worth mentioning that in a recently reported molten salt based rechargeable battery, both the negative and positive electrodes were liquid metals. ${ }^{29,30}$ The third type of electrode is composed of two parts, an inert electronic conductor as the current collector on which is loaded an electrochemically active material. This type is most widely used in commercial rechargeable batteries, such as the copper/graphite negative electrode and lithium cobalt oxide/aluminium positive electrode in lithium ion battery.

In EES devices, electrolytes are equally important as electrodes in terms of their effects on and contributions to the device performance. ${ }^{31-33}$ Although research on electrolytes appears less frequently in high profile publications, improved and new electrolytes are continuously being developed and reported in three categories. These are (i) the traditional solute-solvent solutions involving various functional additives; (ii) liquid salts of wide potential windows, including both high temperature molten salts and room temperature ionic liquids and (iii) solid ionic conductors which promise safer high energy density EES devices. For EES applications, the electrolyte, particularly the solid type, can be used directly to electronically separate but ionically connect the positive and negative electrodes. However, it is more common and practical to use a thin membrane that is permeable to a liquid electrolyte or its ions, and strong enough to prevent direct contact between the two electrodes under the pressure used to assemble the EES device.

In addition to enabling ion transport, electrolytes can also contain redox active ions or molecules to help or enhance charge storage. However, charge storage on the solution side can only be effectively utilized if an ion conducting membrane is used between the two electrodes to prevent shuttling of the oxidized or reduced solution species. This understanding is demonstrated in the so called redox flow battery in which two different electrolytes are used to assist and separate the oxidation based charge storage electrode reaction from that based on reduction. ${ }^{34,35}$ Alternatively, charge storage can also be enhanced if the redox species can be confined inside the electrodes by adsorption or entrapment. An example of this mechanism is reported by using redox active electrolyte in supercapacitors with porous activated carbon electrodes. ${ }^{17,35,36}$

\subsection{Terminologies}

In the above discussion, the terms of positive and negative electrodes are used, although in many publications, 
particularly those on lithium ion batteries, these are replaced by cathode and anode, respectively. By definition, the former emphasizes the relative electrical polarity, and hence the current flowing direction between the two electrodes. The positive electrode has always a more positive potential than that of the negative electrode, and the current only flows from the positive to the negative electrodes. However, the cathode and anode refer to the electrode reactions, i.e., reduction is always on the cathode and oxidation on the anode. Accordingly, both cathode and anode, and positive and negative electrodes can be used for a primary battery. In other words, in the primary battery, the discharging reaction is reduction on the positive electrode which is thus also called cathode, whilst the negative electrode is called anode where the reaction is oxidation.

Partly due to the one-word terms being easier to say and write than the two-word terms, cathode and anode have been used in place of positive and negative electrodes by many authors to describe secondary or rechargeable battery. Although such mixed uses would not affect well informed researchers, these terms should not be misused because in a rechargeable battery, the positive electrode is a cathode in discharging but changes to an anode when charging. The reverse is true for the negative electrode. Therefore, in a secondary battery, it is not appropriate to describe the positive electrode as cathode and the negative electrode as anode. Instead of compromising the rigor of science, and also considering convenience for communication, the author promotes and will use in this article the one-word terms of positrode and negatrode in place of positive electrode and negative electrode, respectively. ${ }^{26,37}$

There are other minor confusing usages of terminologies in the literature on EES devices and materials. For example, current density is the area normalized current, and hence has the dimension of current/area. The respective units can be $\mathrm{A} \mathrm{cm}^{-2}$ or $\mathrm{mA} \mathrm{cm} \mathrm{cm}^{-2}$, for example. However, in many publications, current density is referred to the mass normalized current and given the unit of $\mathrm{A} \mathrm{g}^{-1}$ or $\mathrm{mA} \mathrm{g}^{-1}$. It is obviously confusing to use the same term of current density with two different dimensions or units. The mass normalized current is also called specific current or current load in the literature. Some authors use the term of gravimetric current density, but it still contains the inappropriate word density.

A similar confusion is related with energy density and power density. The proper respective dimensions are energy/volume and power/volume which can have the units of $\mathrm{Wh} \mathrm{L}^{-1}$ and $\mathrm{kW} \mathrm{L}^{-1}$, respectively. However, some authors link energy and power densities with the units of $\mathrm{Wh} \mathrm{kg}^{-1}$ and $\mathrm{kW} \mathrm{kg}^{-1}$ which should really refer to specific energy and specific power. The terms of volumetric energy density and gravimetric energy density are used by some authors in association with units like $\mathrm{Wh} \mathrm{L}^{-1}$ and $\mathrm{Wh} \mathrm{kg}^{-1}$, respectively. However, these two terms are both inappropriate. In the former, the word volumetric is redundant because density is the volume normalized property, whilst in the latter, density is inappropriate. Similar considerations should be applied to volume normalized power or power density and mass normalized power or specific power in relation with the units of $\mathrm{kW} \mathrm{L}^{-1}$ and $\mathrm{kW} \mathrm{kg}^{-1}$, respectively.

The literature is currently presented with different names for hybrid devices. For example, "lithium-ion capacitor" and "sodium-ion capacitor" are fairly popular terms. One of the reasons for this class of hybrid being called capacitor is possibly because they generally perform in similar ways as a capacitor, e.g., linear and triangular galvanostatic charging-discharging plots (GCDs) and rectangular cyclic voltammograms (CVs). However, as mentioned in the Introduction section, because the device includes a lithium-ion (or sodium-ion) battery electrode, the charge storage mechanism is no longer solely capacitive in the device which is strictly speaking not a capacitor. In fact, both the lithium-ion and sodium-ion capacitors are just a special type of supercapattery which also includes other types of asymmetrical charge storage devices. An example of other types of supercapattery is the metal free device of (-) PoAP-CNT $\mid 1.0$ mol L ${ }^{-1} \mathrm{HCl} \mid$ PAn-CNT (+), where CNT stands for carbon nanotubes, PoAP for poly(o-aminophenol), which is a non-conducting and redox active polymer, and PAn for polyaniline, which is a conducting and redox active polymer. ${ }^{4}$

Hybrid capacitor and hybrid supercapacitor also often appear in the literature. Whilst the same explanation given above applies to the terms of capacitor and supercapacitor here, the word hybrid is not unambiguous. For example, to a researcher outside the supercapacitor community, a hybrid may be a device combining a supercapacitor (electrode) with a solar cell (electrode) or a fuel cell (electrode), or it can represent a complex system of several energy generation and storage devices. ${ }^{38-41}$ Thus, the term of hybrid is too broad to help identify and represent the unique battery-supercapacitor combination.

\subsection{Charge storage mechanisms}

In all EES devices, the electrode process holds the main responsibility for charge storage. In principle, an electrode process always involves charging the electric double layer (EDL) via electro-sorption of ions at the electrode/electrolyte interface. However, the charge stored in the EDL has a very low density (charge/area) which is responsible for the measured small capacitance values in the range from 
10 to $40 \mu \mathrm{F} \mathrm{cm}^{-2}$ on flat electrodes of metals or carbon in aqueous electrolytes. The capacitance drops further to around $5 \mu \mathrm{F} \mathrm{cm}^{-2}$ or lower in an organic electrolyte. Thanks to the development of various highly porous and nanostructured materials, such as activated carbon, carbon nanotubes (CNTs) and graphenes, sufficiently high specific capacitance can be achieved, leading to the invention of first generation of supercapacitors. For example, at a specific surface area of $500 \mathrm{~m}^{2} \mathrm{~g}^{-1}$, the specific capacitance can theoretically reach beyond $25 \mathrm{~F} \mathrm{~g} \mathrm{~g}^{-1}$ which is meaningful for energy storage. In practice, because not all the surface area can be accessed by ions, particularly that inside the pores, the measured EDL specific capacitance $\left(\mathrm{C}_{\mathrm{sp}}\right)$ ranges from 30 (for organic electrolytes) to $200 \mathrm{~F} \mathrm{~g}^{-1}$ (for aqueous alkaline electrolytes) on various porous and nanostructured carbon materials. It is interesting to note that because the potential window, $\Delta \mathrm{E}$, is typically $3.0 \mathrm{~V}$ for an organic electrolyte, and $1.2 \mathrm{~V}$ for an aqueous alkaline electrolyte, the specific energy $\left(\mathrm{W}_{\mathrm{sp}}\right)$ of a symmetrical EDL supercapacitor made from activated carbon of $500 \mathrm{~m}^{2} \mathrm{~g}^{-1}$ in specific surface area is typically around $10 \mathrm{Wh} \mathrm{kg}^{-1}$ according to equation 1 below.

$\mathrm{W}_{\mathrm{sp}}=\frac{\mathrm{C}_{\mathrm{cell}} \Delta \mathrm{E}^{2}}{2\left(\mathrm{~m}_{+}+\mathrm{m}_{-}\right)}=\frac{\mathrm{C}_{\mathrm{sp}} \Delta \mathrm{E}^{2}}{8}$

where $\mathrm{m}_{+}=\mathrm{m}_{-}=\mathrm{m}$ is the mass of activated carbon on a single electrode, and $\mathrm{C}_{\text {cell }}$ is cell capacitance and $\mathrm{C}_{\mathrm{sp}}=4 \times \mathrm{C}_{\mathrm{cell}} /\left(\mathrm{m}_{+}+\mathrm{m}_{-}\right)$. For aqueous alkaline electrolytes, $\mathrm{W}_{\mathrm{sp}}=200 \times 1.2 \times 1.2 /(8 \times 3.6)=10.0 \mathrm{Wh} \mathrm{kg}^{-1}$, and for organic electrolytes, $\mathrm{W}_{\mathrm{sp}}=30 \times 3.0 \times 3.0 /(8 \times 3.6)=9.4 \mathrm{Wh} \mathrm{kg}^{-1}$. The specific capacitance of transition metal oxides (TMOs), for example, $\mathrm{RuO}_{2}, \mathrm{MnO}_{2}, \mathrm{SnO}_{2}$, and electronically conducting polymers (ECPs) such as polyaniline (PAn), polypyrrole (PPy) and poly(3,4-ethylenedioxythiophene) (PEDOT) are orders of magnitude higher than that obtainable from carbon based materials. ${ }^{26,42}$ The mechanism of storage in these electrodes is capacitive Faradaic which is commonly called pseudocapacitance.

In classic electrochemistry, the Faradaic process results from the transfer of valence electrons from (or to) ions or molecules at the "electrode | electrolyte" interface (EEI), and it is governed by the Nernst equation, and hence also called the Nernstian process. In cyclic voltammetry, the Nernstian process corresponds to a peak shaped cyclic voltammogram (CV). The concept of Faradaic process can also be applied to describe the electron transfer reactions of the redox active material attached to an electrode. It has been theoretically and experimentally demonstrated that if governed by the Nernst equation, the Faradaic process can take place at the unique redox potentials of a solid material, corresponding to peak shaped CVs. Such
Nernstian processes occur typically in battery electrodes in which the valence electrons of the active material are similar to those in the ions or molecules in the liquid electrolyte.

However, the Nernst equation cannot predict the rectangular $\mathrm{CV}$ s from those redox active materials showing pseudocapacitance. Thus, it has been proposed, as shown in Figure 1, that the Faradaic process is categorized into two types according to the Band model. Firstly, it proceeds in the classic manner via the transfer of localized valence electrons at a fixed potential, $\mathrm{E}^{\circ}$, as governed by the Nernst equation, corresponding to charge storage in a battery electrode and peak shaped CVs, see Figure 1a. Alternatively, the Faradic process can develop from the transfer of delocalized valence electrons which are commonplace in many semiconductor materials, such as those TMOs and ECPs as mentioned above. Delocalized valence electrons spread over a wide range of energy levels, and hence can transfer in a wide range of potentials, leading to capacitive currents as shown by rectangular CVs, see Figure 1b, and triangular GCDs. These features are termed pseudocapacitance because they are the same as the case in EDL capacitance. ${ }^{3,43}$ In summary, the Faradaic process can proceed via either the classic Nernstian route, involving the transfer of localized valence electrons, or the pseudocapacitive path, enabled by the transfer of delocalized valence electrons. For convenience of discussion, the Nernstian process is referred as a noncapacitive Faradaic process, whilst the pseudocapacitive process as a capacitive Faradaic process.

As a typical example of pseudocapacitive electrode materials, $\mathrm{RuO}_{2}$ possess very high specific capacitance $\left(\geq 500 \mathrm{~F} \mathrm{~g}^{-1}\right),{ }^{9}$ which in theory can be used in the fabrication of high energy devices. However, this is only possible if a suitable counter-electrode is utilized, implying that in practice such electrodes are best suited for use in asymmetric devices, ${ }^{3}$ as will be described in Section 2.4. On the other hand, battery storage which is characterized by the non-capacitive Faradaic mechanism could be ascribed to the addition or removal of localized valence electrons into or from fixed energy levels which corresponds to $\mathrm{E}^{\circ}$ in Nernst's equation and results in peak-shaped CVs. ${ }^{3,43-45}$ If $\mathrm{x}$ is the mole fraction of the reduced state, then such non-capacitive Faradaic mechanisms can be described by the Nernst equation (equation 2). ${ }^{46}$

$\mathrm{E}=\mathrm{E}^{\mathrm{o}}+\frac{\mathrm{nF}}{\mathrm{RT}} \ln \left(\frac{1-\mathrm{x}}{\mathrm{x}}\right)$

If all the electrode material participates in the redox reaction under Nernstian conditions, the theoretical charge capacity for the electrode is $\mathrm{Q}_{\mathrm{M}}=\mathrm{nF} / \mathrm{M}$, where $\mathrm{n}$ is the number of electrons transferred, $\mathrm{F}$ the Faraday constant 
(a)

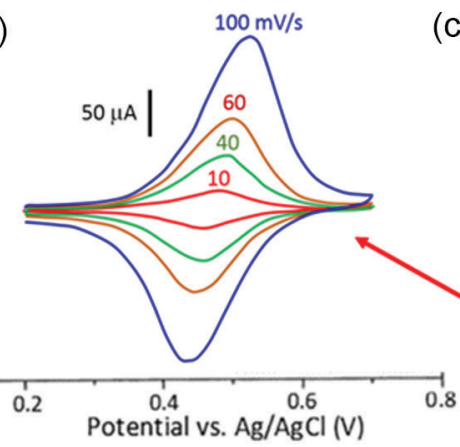

(b)

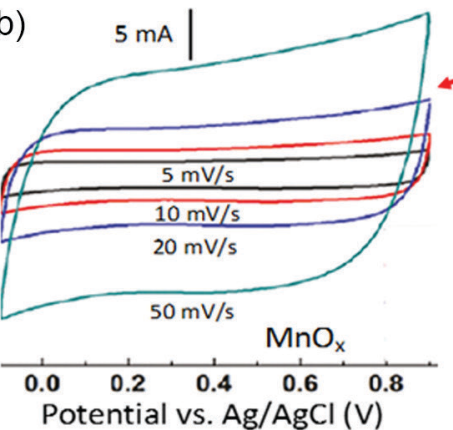

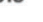

$\mathrm{AgCl}(\mathrm{V})$ (c)

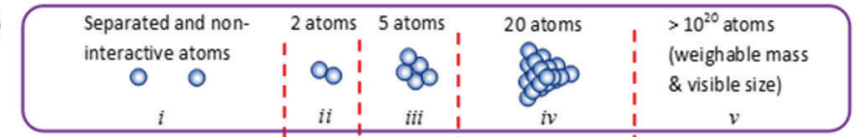

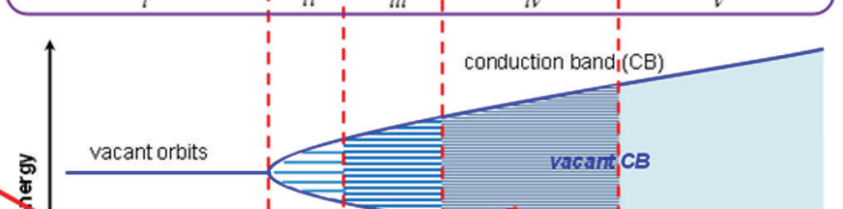
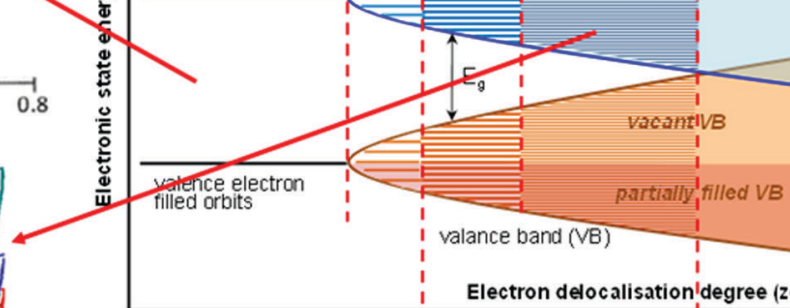

insulators,

localised electrons,

able to store charge.

peak shaped $\mathrm{CV}$.

Figure 1. Charge storage mechanisms. (a) Non-capacitive Faradaic or Nernstian mechanism of ferrocene containing inactive polymer coated electrode in aqueous electrolyte; (b) capacitive Faradaic mechanism of $\mathrm{MnO}_{\mathrm{x}}$ coated electrode in aqueous electrolyte; (c) band model for the description of charge storage mechanisms ((a) is redrawn from reference 45, (b) and (c) are adapted from references 46 and 3, respectively).

(96485 $\mathrm{C} \mathrm{g}^{-1}$ ) and $\mathrm{M}$ the molar mass of the electrode material.

\subsection{Design of asymmetric supercapacitors through the optimal combination of charge storage mechanisms}

Fundamentally, it can be considered that all known supercapacitors are inherently asymmetric. ${ }^{26}$ This is because, even for the case of a device with the same carbon electrodes, charge is stored by anions at the positrode, and cations at the negatrode, and as such the EDL structure and capacitances at both electrodes would be different. ${ }^{26}$ Accordingly, it is necessary to fundamentally understand the charge storage mechanisms of electrodes in order to fabricate optimal devices. In general, practical devices can either combine two capacitive electrodes of either the non-Faradaic or Faradaic kind, or one capacitive electrode and a battery electrode.

In the case of combining two capacitive electrodes, it is important to first ascertain the capacitive potential range (CPR) of the electrode/electrolyte interface (EEI). The CPR is the maximum potential range beyond which non-capacitive Faradaic (or Nernstian) electrode process occurs, or either or both the electrode and electrolyte will decompose. For example, in an acidic aqueous electrolyte, the CPR of PAn is from -0.2 to $0.4 \mathrm{~V} v s$. $\mathrm{Ag} / \mathrm{AgCl}$, although this polymer can undergo reversible charge transfer reactions in a wider range from -0.2 to $0.8 \mathrm{~V}^{44}$ However, for a carbon positrode, the CPR is defined either by the irreversible oxidation/reduction of the electrolyte or one of its components, such as the solvent, or oxidation of the carbon material. Also, for the $\mathrm{MnO}_{2}$ electrode, provided the negative potential end is positively shifted to avoid reduction to the soluble $\mathrm{Mn}^{\mathrm{II}}$ state, a capacitive feature can be obtained for this electrode. ${ }^{3,47}$

Generally, it is important to note that pseudocapacitive electrode materials are usually of low conductivity and hence composited with carbonaceous materials for example carbon nanotubes (CNTs). The resulting composite electrodes display improved capacitive properties. Figure $2 \mathrm{a}$ shows the SEM image of nano-crystaline $\mathrm{MnO}_{2}$ coated on the surface of acid-treated CNT, whilst Figure 2b shows the CVs of the $\mathrm{MnO}_{2}-\mathrm{CNT}$ composite within its CPR.

When designing asymmetric devices with capacitive electrode materials, the expression for charge conservation, $\mathrm{Q}=\mathrm{C}_{\mathrm{P}} \mathrm{U}_{\mathrm{N}}=\mathrm{C}_{\mathrm{N}} \mathrm{U}_{\mathrm{N}}$ can lead to the unequal electrode capacitance strategy that helps engineering optimization. In the preceding expression, $\mathrm{C}_{\mathrm{P}}$ and $\mathrm{U}_{\mathrm{P}}$, and $\mathrm{C}_{\mathrm{N}}$ and $\mathrm{U}_{\mathrm{N}}$ are the capacitance and CPR of the positrode and negatrode, respectively. Assuming that the maximum charging voltage (MCV), $\mathrm{U}=\mathrm{U}_{\mathrm{P}}+\mathrm{U}_{\mathrm{N}}$, is limited by $\mathrm{U}_{\mathrm{P}}$, and $\mathrm{U}_{\mathrm{N}}>\mathrm{U}_{\mathrm{P}}$, then the unequal electrode capacitance expression (equation 3), can be used to calculate the electrode capacitance ratio, and this can be translated into the electrode mass ratio. This strategy was used to increase the $\mathrm{MCV}$ of an activated carbon based EDLC with the aqueous electrolyte 
(a)

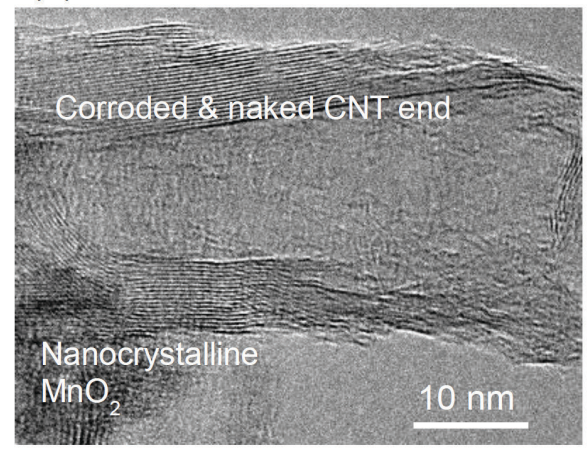

(b)

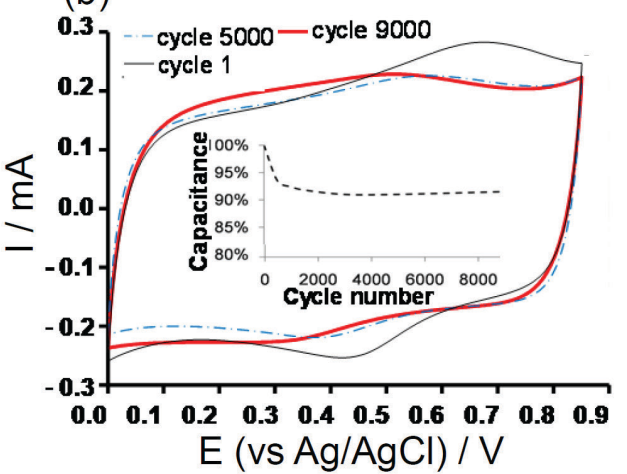

Figure 2. $\mathrm{MnO}_{2}-\mathrm{CNT}$ composite. (a) An SEM image of composite showing the nano-crystalline $\mathrm{MnO}_{\mathrm{x}}$ coated on the surface of the acid treated CNT; (b) rectangular $\mathrm{CVs}$ of the $\mathrm{MnO}_{2}-\mathrm{CNT}$ composite operating within the CPR (adapted from reference 48).

of $0.3 \mathrm{~mol} \mathrm{~L}^{-1} \mathrm{~K}_{2} \mathrm{SO}_{4}$ from $1.6 \mathrm{~V}$ with equal electrode mass, to $1.9 \mathrm{~V}$ with a positrode to negatrode mass ratio of $4: 3 .{ }^{49}$

$\mathrm{U}=\mathrm{U}_{\mathrm{P}}\left(1+\frac{\mathrm{C}_{\mathrm{P}}}{\mathrm{C}_{\mathrm{N}}}\right)$

Figure 3 a shows the inherent asymmetric property of the unit EDLC cell with activated carbon positrode and negatrode. This cell with unequal electrode masses was also shown to be relatively stable after long duration cycling (see Figure $3 \mathrm{~b}$ ). It was also calculated that relative to the total mass of the electrodes in the cell, there was a $2 \%$ decrease in the cell capacitance, however, the increased MCV resulted in a $38 \%$ increase in the specific energy. ${ }^{48}$

The conservation of charge expression written in terms of the specific capacitances can in general be used to ascertain the mass ratio when capacitive electrodes are to be combined. For example this has been used to design the cell (-) AC 0.5 mol L-1 $\mathrm{Na}_{2} \mathrm{SO}_{4} \mid \mathrm{MnO}_{2}(+)$, where $\mathrm{AC}$ is activated carbon. It was shown that a positrode to negatrode mass ratio of 2.5:1 resulted in a cell which showed good cycling performance at the cell voltage of $2.2 \mathrm{~V} \cdot{ }^{49}$ In these cells using a capacitive Faradaic (pseudocapacitive)

(a)

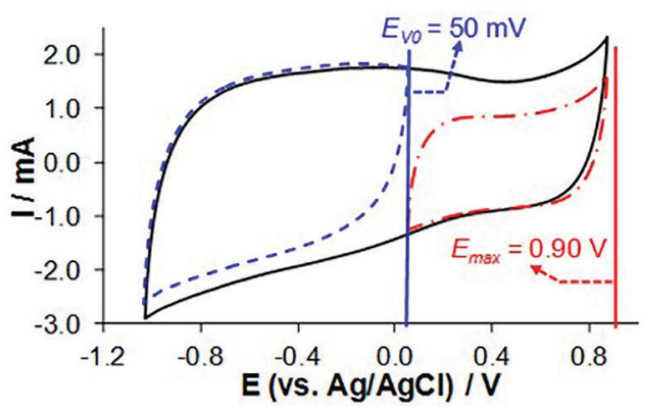

TMO electrode in combination with an activated carbon electrode, it is important that the mass ratio of the electrodes are such that at the maximum charging voltage the polarization of the TMO electrode is within its capacitive range, whilst Faradaic reactions at the EDL electrode, if any, are reversible, for example the reversible electro-sorption and electro-desorption of hydrogen. This is evident in the cell (-) AC $\mid 0.5$ mol L-1 $\mathrm{Na}_{2} \mathrm{SO}_{4} \mid \mathrm{MnO}_{2}(+)$ in which an increase in the polarization of the positrode towards higher potentials could lead to irreversible Faradaic reactions. ${ }^{50}$ Essentially, the same applies to the case of conducting polymers when they are used in symmetric cells with similar polymer materials or paired with EDL electrodes. This implies that, when capacitive Faradaic electrodes are used in designing supercapatteries, the calculation of the mass of active material to be loaded on the electrode should be done in such a way that the polarization should avoid irreversible redox reactions. This strategy has thus been used to design a cell with composite electrodes of TMO and CNTs, i.e., (-) $\mathrm{SnO}_{2}-\mathrm{CNT}\left|2.0 \mathrm{~mol} \mathrm{~L}^{-1} \mathrm{KCl}\right|$ $\mathrm{MnO}_{2}-\mathrm{CNT}(+)$, which operated at an MCV of $1.8 \mathrm{~V}^{50}$ Ordered mesoporous carbon electrodes with nitrogen functionalities displaying impressive EDL and capacitive

(b)

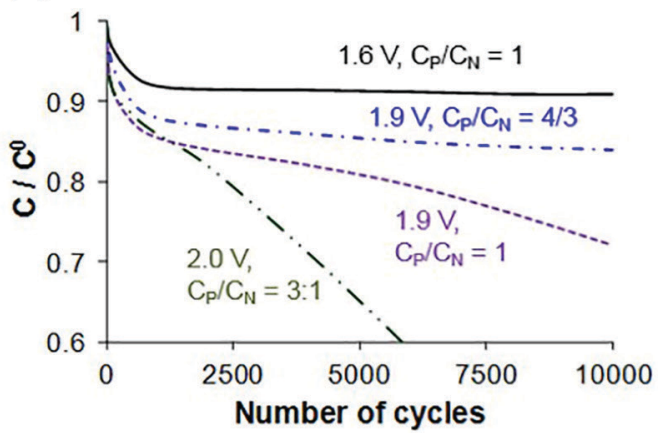

Figure 3. Activated carbon in $0.3 \mathrm{~mol} \mathrm{~L}^{-1} \mathrm{~K}_{2} \mathrm{SO}_{4}$. (a) Unit cell showing the CPR, and the use of the unequal electrode capacitance strategy to extend cell voltage; $\mathrm{E}_{\mathrm{v} 0}$ is the position of electrode potential at zero cell voltage; (b) capacitance fade on cycling of EDL capacitors with different electrode mass ratios (adapted from reference 49). 
Faradaic properties have also been recently reported. ${ }^{51}$ In this case, surface confined redox reactions resulted in high specific electrode capacitance values which were exploited to design improved capacitive cells.

It is worth pointing out that there are also noncapacitive Faradaic TMO electrodes which can be used as either or both of the negatrode and positrode in the design of supercapattery. An important example is the cell using the NiO- $\operatorname{In}_{2} \mathrm{O}_{3}$ composite electrode, which can be polarized in wide positive and negative electrode potential windows. This cell with the configuration (-) NiO- $\operatorname{In}_{2} \mathrm{O}_{3} \mid$ $3.0 \mathrm{~mol} \mathrm{~L}^{-1} \mathrm{KOH} \mid \mathrm{NiO}-\mathrm{In}_{2} \mathrm{O}_{3}(+)$ was able to charge to a maximum voltage of $1.6 \mathrm{~V}$, and displayed good cycling capabilities, ${ }^{52}$ with performance features that are best described as a supercabattery which will be further described and discussed in the next section (see Table 1).

\subsection{Supercapattery: combination of a Nernstian negatrode and a capacitive positrode}

In this case, the capacitive positrode may either display pseudocapacitance or EDL capacitance, whilst the negatrode is Nernstian, for example, lithium metal or a lithiated material. Although the descriptions given herein would utilize lithium metal as the negatrode, in practical applications, Nernstian electrodes with sufficiently reversible redox reactions can also be used.

When combining a capacitive positrode and a Nernstian negatrode together in one cell, the charge conservation equation can be written as equation 4 .

$\mathrm{Q}_{-}=\mathrm{m}_{-} \mathrm{Q}_{\mathrm{sp}-}=\mathrm{m}_{+} \mathrm{C}_{\mathrm{sp}+} \Delta \mathrm{E}_{+}=\mathrm{Q}_{+}$

where $\mathrm{m}_{-}$and $\mathrm{Q}_{-}, \mathrm{m}_{+}$and $\mathrm{Q}_{+}$, are the mass and total charge stored in the negatrode and positrode respectively. $\mathrm{Q}_{\mathrm{sp}-}$ is the specific charge of the negatrode, i.e., $\mathrm{Q}_{\text {sp- }}=\mathrm{nF} / \mathrm{M}$.

Consider the situation where an activated carbon electrode with $\mathrm{C}_{\mathrm{sp}, \mathrm{C}}=200 \mathrm{~F} \mathrm{~g} \mathrm{~g}^{-1}$, and $\Delta \mathrm{E}=4.0 \mathrm{~V}$ is used as the positrode, then $\mathrm{Q}_{\mathrm{sp}, \mathrm{C}}=\mathrm{C}_{\mathrm{sp}, \mathrm{C}} \Delta \mathrm{E}=800 \mathrm{C}$. If the negatrode is lithium metal, then $\mathrm{Q}_{\mathrm{sp}, \mathrm{Li}}=\mathrm{nF} / \mathrm{M}_{\mathrm{Li}}=13.9 \mathrm{kC} \mathrm{g}^{-1}$ $\left(=3861 \mathrm{mAh} \mathrm{g}^{-1}\right.$ ) where $\mathrm{n}=1$, and $\mathrm{M}_{\mathrm{Li}}=6.941 \mathrm{~g} \mathrm{~mol}^{-1}$. Accordingly $\mathrm{m}_{+} / \mathrm{m}_{-}=\mathrm{m}_{\mathrm{C}} / \mathrm{m}_{\mathrm{Li}}=\mathrm{Q}_{\mathrm{sp}, \mathrm{Li}} /\left(\mathrm{C}_{\mathrm{sp}, \mathrm{C}} \Delta \mathrm{E}\right)=17.4$, thus implying that $\mathrm{C}_{\mathrm{sp}, \mathrm{cell}}=\mathrm{C}_{\mathrm{cell}} / \mathrm{m}_{\mathrm{C}} \mathrm{ca}$. $\mathrm{C}_{\mathrm{sp}, \mathrm{C}}$. In such a situation, the energy of the supercapattery can then be written as equation 5 :

$\mathrm{W}_{\mathrm{sp}}=\frac{\mathrm{C}_{\mathrm{sp}, \mathrm{cell}}}{2}\left(\mathrm{U}_{\text {max }}^{2}-\mathrm{U}_{\text {min }}^{2}\right)$

If as theoretically shown in Figure $4 \mathrm{a}, \mathrm{U}_{\max }=4.5 \mathrm{~V}$, and $\mathrm{U}_{\text {min }}=0.5 \mathrm{~V}$, the specific energy of the cell can be calculated to be $\mathrm{W}_{\mathrm{sp}}=(200 / 2)\left(4.5^{2}-0.5^{2}\right)=555.6 \mathrm{Wh} \mathrm{kg}^{-1}$. Following this principle of design, a simple supercapattery cell of (-) $\mathrm{Li} / \mathrm{Li}^{+}\left|\mathrm{IL}+\mathrm{LiClO}_{4}\right| \mathrm{AC}(+)$ was fabricated, where the electrolyte was $\mathrm{LiClO}_{4}$ dissolved in a solution of gamma-butyrolactone ( $\gamma$-GBL) in an ionic liquid (IL) of 1-butyl-1-methylpyrrolidinium (see Figure 4b). This cell displayed a specific energy value of $230 \mathrm{Wh} \mathrm{kg}^{-1} .^{18}$

Alternatively, the positrode could be pseudocapacitive, with the negatrode been a lithium metal or lithiated material according to Figure $4 \mathrm{c}$. In this case, if $\Delta \mathrm{E}=1.0 \mathrm{~V}$, and $\mathrm{C}_{\text {sp.pseudo }}=500 \mathrm{~F} \mathrm{~g}^{-1}$, it follows that $\mathrm{C}_{\text {cell }}$ ca. $\mathrm{m}_{\text {pseudo }} \mathrm{C}_{\text {sp,pseudo }}$ ca. $500 \mathrm{~F} \mathrm{~g}^{-1}$. Assuming $\mathrm{U}_{\max }=4.5 \mathrm{~V}$, with $\mathrm{U}_{\min }=3.5 \mathrm{~V}$ as hypothetically shown in Figure 4c, then from equation 5, $\mathrm{W}_{\mathrm{sp}}=555.6 \mathrm{Wh} \mathrm{kg}^{-1}$. A practical demonstration of this strategy has been shown in the cell of $(-) \mathrm{Li} / \mathrm{Li}^{+}$ buffer-layer | solid-electrolyte | aqueous-electrolyte | $\mathrm{RuO}_{2}$-nanosheet (+), displaying an $\mathrm{MCV}$ of $3.8 \mathrm{~V}$. Another related cell with the positrode replaced by $\mathrm{MnO}_{2}$ displayed an MCV of $4.0 \mathrm{~V}$. In these cells, the buffer-layer, which was used to stabilize the Li metal negatrode, was a polymer electrolyte comprising of polyethylene oxide with $\mathrm{Li}\left(\mathrm{CF}_{3} \mathrm{SO}_{2}\right)_{2} \mathrm{~N}$. The solid-electrolyte, a water stable LISICON-type glass ceramic was in contact with an aqueous electrolyte of $1.0 \mathrm{~mol} \mathrm{~L}^{-1} \mathrm{Li}_{2} \mathrm{SO}_{4}$ at a temperature of $60{ }^{\circ} \mathrm{C} .{ }^{9}$

It should be noted that when the negatrode is made of a lithiated carbon material, the mass of the negatrode may not be negligible compared to that of the capacitive positrode. Thus, the total mass of both electrodes should be considered in the design, although the value of $\mathrm{C}_{\mathrm{sp}, \mathrm{cell}}$ would still tend to that of the capacitive positrode because the apparent capacitance of the Nernstian negatrode is usually significantly greater than that of the positrode. Accordingly, the apparent cell capacitance is thus normalized by the factor $\left(\mathrm{m}_{+}+\mathrm{m}_{-}\right)$, and this could reduce the specific energy of the cell by as much as $25 \%$. Generally, in the design of such cells, the capacitive electrodes should have a high enough CPR, and the reaction kinetics of the Nernstian negatrode should also be highly reversible.

A common question about supercapattery is how it is different from some existing hybrid EES devices, such as the Li-ion and Na-ion capacitors. Such a question is more likely the result of terminological misunderstanding because it is similar to a question about the difference between rechargeable battery and Li-ion battery. In other words, the term of supercapattery aims to capture a broad class of possible combinations of capacitive and Nernstian electrodes in EES cell designs. ${ }^{2,53}$ Thus, Li-ion and Na-ion capacitors are, in the view of the authors, a special type of supercapattery which also includes other types of hybrid EES devices as explained in previous sections. 
(a)

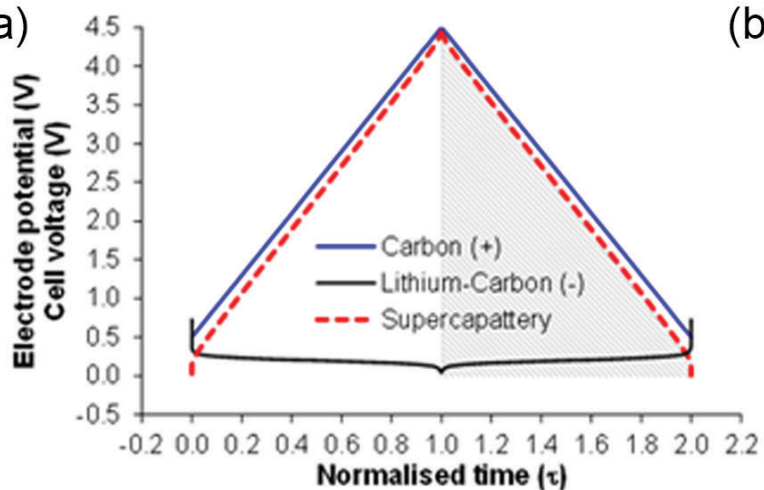

Normalised time $(\tau)$

(c)

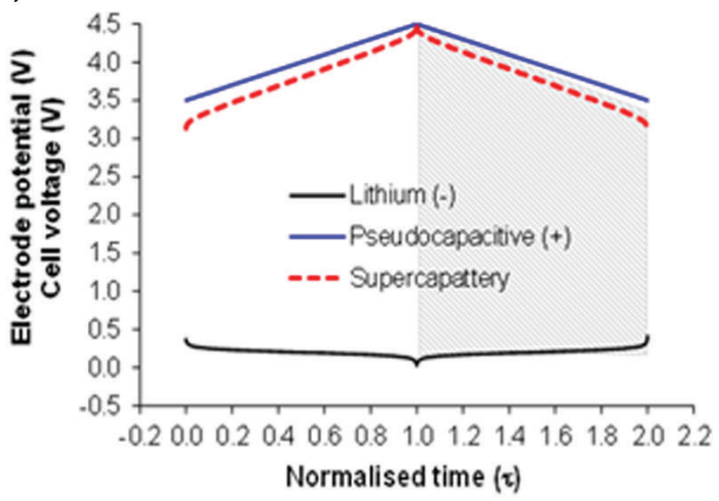

(b)

(+) $\mathrm{AC}(110 \mathrm{~F} / \mathrm{g})\left|\mathrm{IL}+\mathrm{LiClO}_{4}\right| \mathrm{Li} / \mathrm{Li}^{+}(-)$

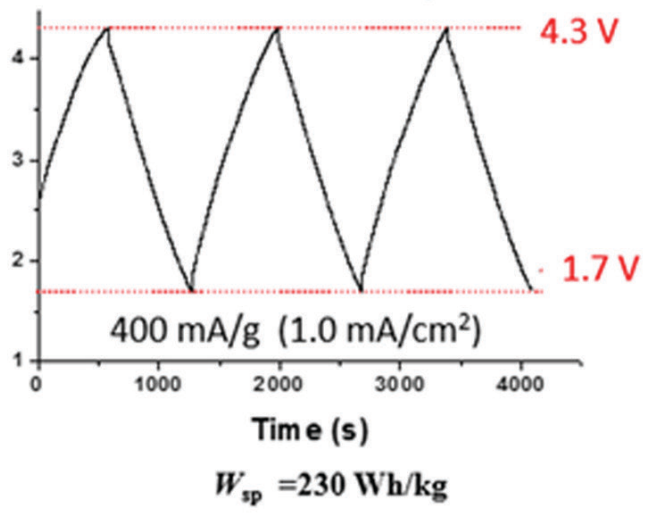

(d)

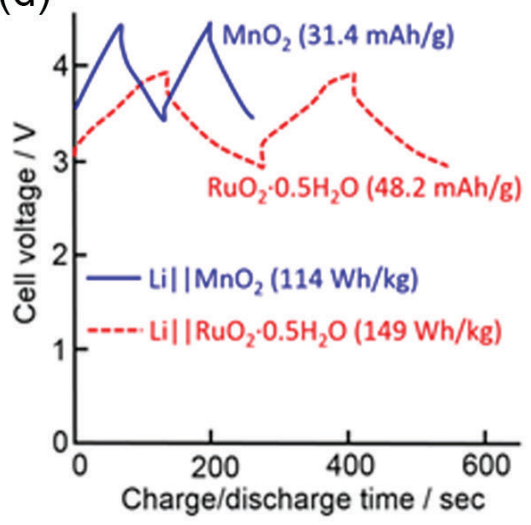

Figure 4. GCD profiles of supercapattery. (a) A hypothetical cell with an EDL capacitive positrode and the Li metal negatrode; (b) a representative prototype cell of (a) with the configuration (-) $\mathrm{Li}^{2} \mathrm{Li}^{+}\left|\mathrm{IL}+\mathrm{LiClO}_{4}\right| \mathrm{AC}(+)$; (c) a hypothetical cell with a pseudocapacitive positrode and the $\mathrm{Li}$ metal negatrode; (d) a prototype cell of (c) with the configuration (-) $\mathrm{Li}^{\prime} \mathrm{Li}^{+} \mid$buffer-layer $\mid$solid-electrolyte $\mid$aqueous-electrolyte $\mid \mathrm{RuO}^{-n a n o s h e e t}$ or $\mathrm{MnO}_{2}(+)$ (a) and (c) are adapted from reference 3, (b) from reference 18 and (c) is redrawn from reference 9).

It is acknowledged that as reported in the literature, there are some redox active TMO materials, such as $\mathrm{NiO}$ and $\mathrm{Co}_{2} \mathrm{O}_{3}$ and their derivatives, which are capable of Nernstian charge storage, but also nanostructured to offer at least EDL capacitance. As a result, they are characterized by peak shaped CVs and non-linear GCDs, and can offer fairly high storage capacity as battery electrode materials. More importantly, these TMOs show fast charge storage kinetics and long cycle life that are comparable with the features of pseudocapacitive materials for supercapacitor. Strictly speaking, EES devices made from these TMOs are not supercapacitors, but also differ from conventional batteries. Obviously, as discussed in the Introduction section, these TMOs actually fall into the category of supercapattery that combines battery and supercapacitor merits at the electrode material level. However, because their performance features as represented by the peakshaped CVs are more battery-like, the EES devices made from these TMOs are given the name of supercabattery which is a unique type of supercapattery but displays dominantly Nernstian features with recognizable capacitive contribution to charge storage. Notable examples of supercabattery include (-) $\mathrm{Li}_{4} \mathrm{Ti}_{5} \mathrm{O}_{12}\left|\mathrm{Li}^{+}\right| \mathrm{AC}(+)$, and (-) $\mathrm{AC}\left|\mathrm{Li}^{+}\right| \mathrm{LiMn}_{2} \mathrm{O}_{4}(+),{ }^{54}$ and the earlier described TMO symmetrical cell of (-) NiO- $\mathrm{In}_{2} \mathrm{O}_{3}\left|3 \mathrm{~mol} \mathrm{~L}^{-1} \mathrm{KOH}\right|$ NiO- $\mathrm{In}_{2} \mathrm{O}_{3}(+) .{ }^{52}$ Table 1 illustrates the possible pairing of electrode materials with different charge storage mechanisms and their categorization based on the general terms of supercapacitor, supercapattery, supercabattery, and battery. This table also shows some representative performance metrics for these EES cells.

It is also important to point out that the Nernstian storage mechanism can also be obtained from redox species dissolved in the electrolyte of a supercapacitor, particularly the EDLC. This has been demonstrated by dissolving transition metal ions, ${ }^{55}$ or quinones, ${ }^{56}$ in conventional acidic electrolytes, or the use of aqueous electrolytes of halides ${ }^{37}$ which are inherently redox active as electrolytes in EDLCs based on porous carbon materials. In these applications, the reaction of the dissolved redox species at the carbon electrode should be reversible and stable at the $\mathrm{pH}$ of the electrolyte solution, whilst the product of the redox reaction must effectively adsorb inside the pores of the electrode in order to reduce self-discharge. ${ }^{17,57}$ Since these devices offer both capacitive 
Table 1. Pairing of electrode materials to form different classes of EES devices such as supercapacitor, battery, supercapattery and supercabattery, and the performance metrics of some representative cells (adapted from reference 2 and 19)

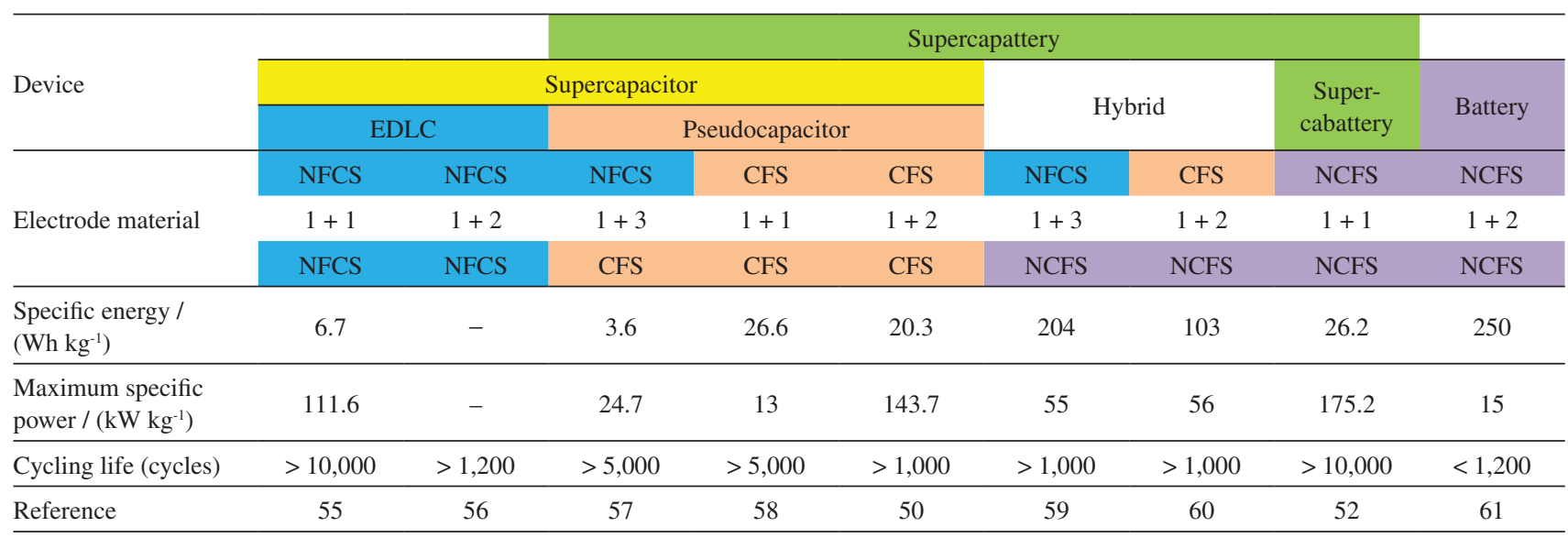

NFCS: non-Faradaic capacitive storage = EDLC storage; CFS: capacitive Faradaic storage = pseudocapacitive storage; NCFS: non-capacitive Faradaic Storage $=$ battery-type storage $=$ Nernstian storage $; 1+1$ : symmetrical device of the same electrode material; $1+2$ : asymmetrical device of different materials with the same storage mechanism; $1+3$ : asymmetrical device of different materials with different storage mechanisms.

and Nernstian mechanisms for charge storage in the same device, they are also a special type of supercapattery. From the point of view of engineering, increasing charge capacity simply by introducing additives to the electrolyte is surely a facile and promising means of improving the performance of supercapattery. However, obtaining the charge capacity at high voltages, and reducing self-discharge without ionselective membranes, are aspects that still warrant more investigations in the use of dissolved redox species.

\subsection{Fabrication of practical supercapatteries}

In practice, the current collector which acts as the substrate for loading active materials on the electrode must be chemically and electrochemically stable in the electrolyte used in the EES devices. In most commercial supercapacitors, the substrates are usually metal foils on which the active materials are loaded by coating, for example. Afterwards, the foil can then be folded into the cylindrical or prismatic shapes of the casing.

Screen-printing has been shown to be an effective way of coating various electrode substrates, leading to mechanically robust coatings that display good capacitive properties. ${ }^{65}$ Figure 5a shows an example of the printing ink formed by mixing composite of PPy and CNTs with appropriate additives. The advantage of screen printing is the good control of the thickness of the active material coating in a large area of current collector plate as shown in Figures $5 b$ and $5 c$. It can be noticed in Figures $5 d$ and $5 \mathrm{e}$ that although having very different morphologies, both activated carbon and the PPy-CNT composite can be printed to very comparable appearances. The printed electrodes were combined into a stack of three internally connected cells, and performed to expectation as shown in Figure 5f.

A main strategy for the design of commercially scalable EES devices is the bipolar stack, which is fabricated by the internal serial connection of neighboring supercapattery cells with a bipolar plate. The main advantage of this design is that it uses fewer current collectors. For example, with $\mathrm{n}$ connected cells, the bipolar internal connection design would require $n+1$ current collectors, instead of $2 n$ current collectors in the case of external connections. Such space and material efficient designs are particularly useful when the active material is made into a thick and large blanket $(\geq 5 \mathrm{~mm}$ in thickness and $120 \times 120 \mathrm{~mm}$ in area) to be attached to the current collector substrate. Figure 6 illustrates the bipolar internal connection design used in the fabrication of a stack comprising of 19 single cells with the configuration of (-) Ti $|\mathrm{CMPB}| 0.5 \mathrm{~mol} \mathrm{~L}^{-1} \mathrm{KCl} \mid$ PPy-CNT $\mid \mathrm{Ti}(+)$, where CMPB is a commercially available activated carbon black, PPy-CNT the composite of PPy and acid-treated CNTs, and Ti the titanium plate current collector. ${ }^{60}$

In general, such a stack of bipolarly connected cells are characterized by small stack weight and volume, and hence higher specific energy and energy density. The parallel arrangement of the cells and their plate-shaped components also allows for easy dissipation of heat generated during the operation. Further, the bipolar stack design is advantageous in terms of process engineering because it would allow the separate manufacturing of individual cell components which are then assembled into the final stack. However, the bipolar stack design needs to use bipolar plates that are non-permeable to any component of the electrolyte, and also proper sealing of each cell to prevent any leak 


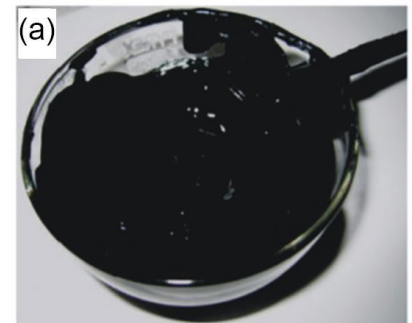

Printing ink

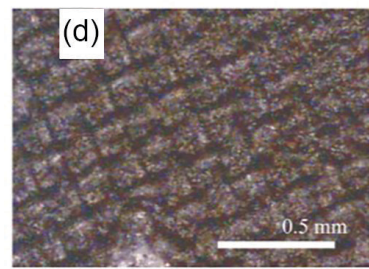

Activated carbon

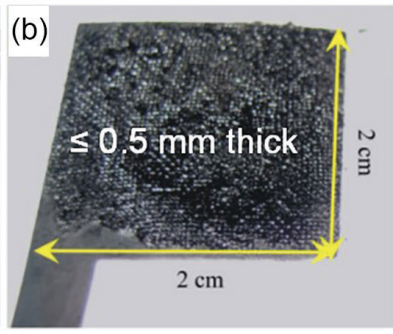

Activated carbon

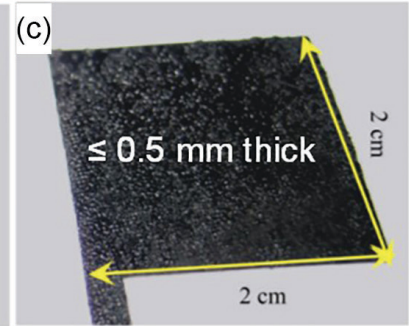

PPy-CNT

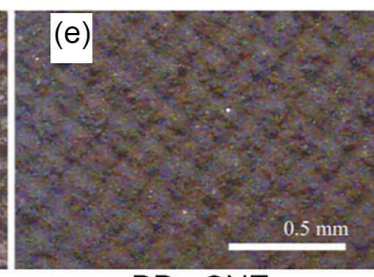

PPy-CNT

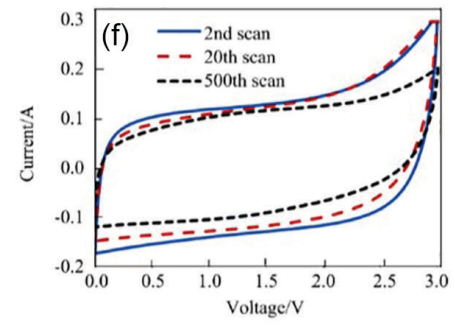

Figure 5. (a) Printing ink of PPy-CNT composite. Screen printed (b) activated carbon and (c) PPy-CNT composite on titanium plate; enlarged views of the surfaces of screen printed (d) activated carbon and (e) PPy-CNT composite; (f) CVs of a stack of three bipolarly connected cells of (-) $\mathrm{AC} \mid$ aqueous $3 \mathrm{~mol} \mathrm{~L}^{-1} \mathrm{KCl} \mid \mathrm{PPy}-\mathrm{CNT}(+)$, showing the expected working voltage of $3.0 \mathrm{~V}$ (adapted from reference 65).
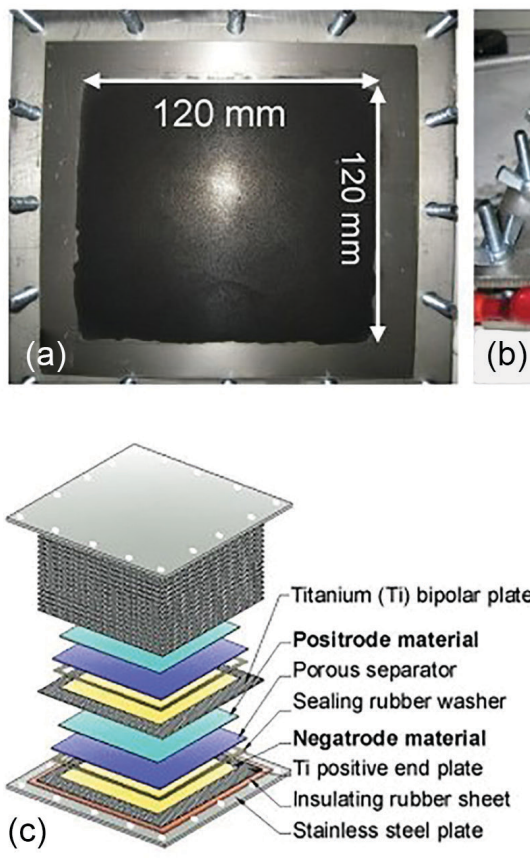
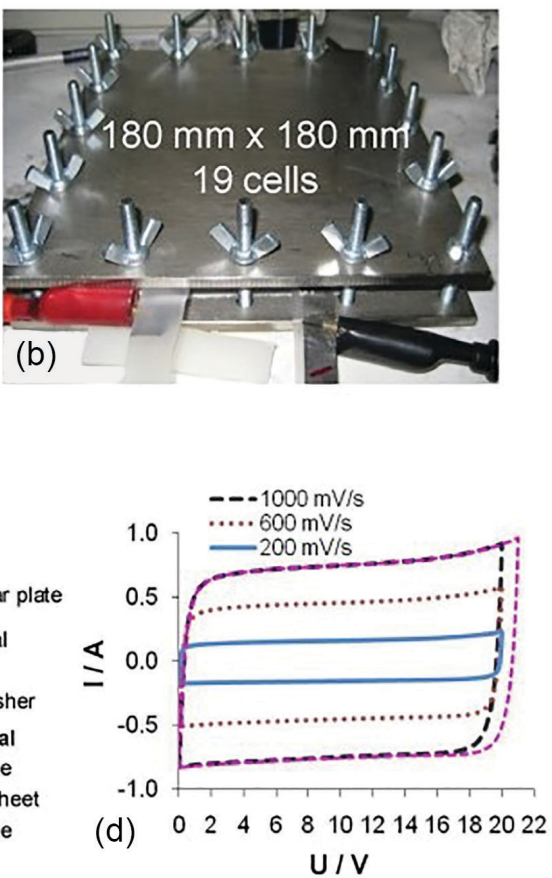

Figure 6. Bipolar stack of 19 supercapattery cells. (a) Dimensions of the active material blanket placed on the current collector; (b) top view of the stack showing the fastening screws used to seal all the components of the stack; (c) exploded view of the stack showing all the components; (d) CVs of the bipolar stack 19 supercapattery cells, showing good capacitive features and a MCV of $20.0 \mathrm{~V}$ (adapted from reference 57).

of the liquid electrolyte that can ionically short-circuit the stacked cells. Another engineering challenge to the stack design with internal bipolar connections is that the stack performance is largely determined by the cell with any technical fault. For externally connected cells, it is possible to simply replace the faulty cell with a good one, but it is unfortunately impossible to do the same in the stack of internally connected cells. Thus, the accurate equalization of individual cell components of each type is imperatively crucial to ensure the realization of the designed performance of the final stack.

In addition to large stacks of supercapattery, supercapacitors, or other type of EES device, the recent approach to designing micro-supercapacitors for microelectronic applications also utilized internal serial connections. For example, direct laser writing of the composite of laser scribed graphene (LSG) and $\mathrm{Fe}_{3} \mathrm{O}_{4}$ was adapted in the design of internally serialized micro- 
supercapacitors. ${ }^{66}$ Also, solid-state supercapacitors using a polymeric electrolyte and CNT electrodes were adopted in fabrication of a bipolarly connected stack of 3 solidstate supercapacitor cells. ${ }^{67}$ Such applications of the stack of internally connected cells to micro-electronics and solid-state supercapacitors generally show the versatility of the bipolar stack design for manufacturing high voltage and space-material efficient cells for the ever expanding applications of supercapacitors and supercapatteries.

\section{Conclusion}

Supercapattery is explained as a generic term to represent a large category of hybrid electrochemical energy storage devices that combine the merits of supercapacitor and rechargeable battery. It can be achieved either by balanced pairing of a supercapacitor electrode with a battery electrode, or by making the electrodes from active materials that are capable of both capacitive and Nernstian charge storage, or by addition of redox species in the electrolyte of a supercapacitor so that the device can store charge via both the capacitive and Nernstian mechanisms. In the design of supercapattery, it is important to ascertain the charge storage mechanisms of the electrodes to be used, particularly with reference to the capacitive potential range of the nonFaradaic capacitive (EDL capacitive) or the capacitive Faradaic (pseudocapacitive) electrode, and the redox potential and charge capacity of the Nernstian electrode. Proper understanding of these electrode charge storage mechanisms can then be used to inform the engineering design and manufacture of optimal cells. Furthermore, high energy density supercapatteries can also be designed and manufactured in a space-material efficient manner through the utilization of impermeable bipolar plates to internally and serially stack multiple supercapattery cells.

\section{Acknowledgments}

This work received funding from the International Doctoral Innovation Centre, Ningbo Education Bureau, Ningbo Science and Technology Bureau, and the University of Nottingham, the EPSRC (EP/J000582/1, GR/R68078), E.ON AG (Energy Storage 2007), and Ningbo Municipal Government (3315 Plan and 2014A35001-1). The authors also thank the invaluable contributions from current and past members of the Electrochemical Technologies Group in both Nottingham and Ningbo.

Bamidele Akinwolemiwa holds a BSc in Physics (2011) from Kogi State University, Nigeria, and an MSc in

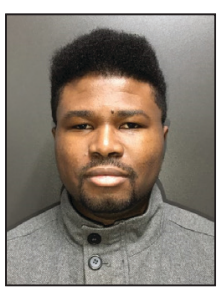

Sustainable Energy Engineering (2013) from The University of Nottingham UK. He is currently a PhD candidate with the International Doctoral Innovation Centre at The University of Nottingham Ningbo China. His PhD research conducted under the supervision of Prof George Z. Chen is focused on investigating the use of redox electrolytes in supercapacitors and supercapatteries. His general research interests are on the electrochemistry of materials (electrodes and electrolytes) for the development and optimisation of electrochemical energy storage devices.

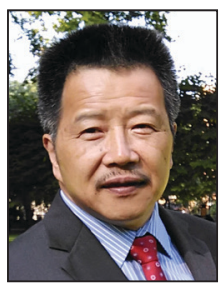

George Zheng Chen obtained his PhD in 1992 from University of London (supervisor: Prof W. John Albery, FRS, Imperial College of Science, Technology and Medicine) and is now Li Dak Sum Chair Professor in the University of Nottingham Ningbo China. His research aims at electrochemical and liquid salts innovations for materials, energy and environment, producing 35 patents (including the Fray-Farthing-Chen Cambridge Process), 220 peer reviewed articles in journals and books, and over 380 invited and contributed presentations at conferences and seminars. On 28 December 2017, Web of Science reported an h-index of 53 and 10123 citations for his 215 publications.

\section{References}

1. Larcher, D.; Tarascon, J.-M.; Nat. Chem. 2014, 7, 19.

2. Chen, G. Z.; Prog. Nat. Sci.: Mater. Int. 2013, 23, 245.

3. Chen, G. Z.; Int. Mater. Rev. 2017, 62, 173.

4. Hu, D.; Peng, C.; Chen, G. Z.; ACS Nano 2010, 4, 4274.

5. Kim, E.; Leverage, W. T.; Liu, Y.; White, I. M.; Bentley, W. E.; Payne, G. F.; Analyst 2017, 142, 4058.

6. Hung, C. J.; Lin, P.; Tseng, T. Y.; J. Power Sources 2014, 259 , 145.

7. Sivakkumar, S. R.; Nerkar, J. Y.; Pandolfo, A. G.; Electrochim. Acta 2010, 55, 3330.

8. Kuratani, K.; Yao, M.; Senoh, H.; Takeichi, N.; Sakai, T.; Kiyobayashi, T.; Electrochim. Acta 2012, 76, 320.

9. Makino, S.; Shinohara, Y.; Ban, T.; Shimizu, W.; Takahashi, K.; Imanishi, N.; Sugimoto, W.; RSC Adv. 2012, 2, 12144.

10. Wang, R. T.; Yan, X. B.; Lang, J. W.; Zheng, Z. M.; Zhang, P.; J. Mater. Chem. A 2014, 2, 12724.

11. Company showcase; Renewable Energy Focus, 2008, 9, 10. DOI: 10.1016/S1471-0846(08)70108-2. 
12. http://www.birmingham.ac.uk/Documents/international/u21brochure.pdf, accessed on October 8, 2017.

13. http://ma.ecsdl.org/content/MA2011-02/11/559.full.pdf, accessed on October 15, 2017.

14. Chae, J. H.; Zhou, X. H.; Chen, G. Z.; Int. J. Sustainable Green Energy 2012, 2, 41.

15. https://www.chemistryworld.com/news/from-nutshell-tosupercapattery/8078.article, accessed on October 15, 2017.

16. Huang, W.-J.; Tai, C.-H.; Liou, Y.-J.; US pat. 20140176075-A1, 2014.

17. Akinwolemiwa, B.; Peng, C.; Chen, G. Z.; J. Electrochem. Soc. 2015, 162, A5054.

18. Yu, L. P.; Chen, G. Z.; Faraday Discuss. 2016, 190, 231.

19. Yu, L.; Chen, G. Z.; J. Power Sources 2016, 326, 604.

20. Liang, X. T.; Pan, W.; Chen, K. F.; Xue, D. F.; Chin. J. Appl. Chem. 2016, 33, 867.

21. Shao, H.; Padmanathan, N.; McNulty, D.; O’Dwyer, C.; Razeeb, K. M.; ACS Appl. Mater. Interfaces 2016, 8, 28592.

22. Padmanathan, N.; Shao, H.; McNulty, D.; O’Dwyer, C.; Razeeb, K. M.; J. Mater. Chem. A 2016, 4, 4820.

23. Zhao, L.-P.; Meng, W.-S.; Wang, H. Y.; Qi, L.; Acta Phys.-Chim. Sin. 2017, 33, 787.

24. Alguail, A. A.; Al-Eggiely, A. H.; Grgur, B. N.; J. Saudi Chem. Soc. 2017, 21, 575.

25. An, W. D.; Gao, Y. F.; Liu, J. R.; ChemistrySelect 2017, $2,7372$.

26. Akinwolemiwa, B.; Wei, C. H.; Chen, G. Z.; Electrochim. Acta 2017, 247, 344; Narayana, A. L.; Dhananjaya, M.; Prakash, N. G.; Hussain, O. M.; Julien, C. M.; Ionics 2017, 23, 3419.

27. Chen, K. F.; Xue, D. F.; Chem. Rec. 2017, in press, DOI:10.1002/ tcr.201700037.

28. Bradwell, D. J.; Kim, H.; Sirk, A. H. C.; Sadoway, D. R.; J. Am. Chem. Soc. 2012, 134, 1895.

29. Ning, X.; Phadke, S.; Chung, B.; Yin, H.; Burke, P.; Sadoway, D. R.; J. Power Sources 2015, 275, 370.

30. Wang, Y.; Zhong, W.-H.; ChemElectroChem 2015, $2,22$.

31. Zhong, C.; Deng, Y. D.; Hu, W. B.; Qiao, J. L.; Zhang, L.; Zhang, J. J.; Chem. Soc. Rev. 2015, 44, 7484.

32. Xia, L.; Yu, L. P.; Hu, D.; Chen, G. Z.; Mater. Chem. Front. 2017, 1, 584.

33. Leung, P.; Li, X. H.; Ponce de León, C.; Berlouis, L.; John Low, C. T.; Walsh, F. C.; RSC Adv. 2012, 2, 10125.

34. Skyllas-Kazacos, M.; Grossmith, F.; J. Electrochem. Soc. 1987, 134, 2950.

35. Shimooka, T.; Yamazaki, S.; Sugimoto, T.; Jyozuka, T.; Teraishi, H.; Nagao, Y.; Oda, H.; Matsuda, Y.; Ishikawa, M.; Electrochemistry 2007, 75, 273.

36. Lota, G.; Frackowiak, E.; Electrochem. Commun. 2009, 11, 87; Gastol, D.; Walkowiak, J.; Fic, K.; Frackowiak, E.; J. Power Sources 2016, 326, 587.

37. Chen, G. Z.; Positrode and Negatrode, ResearchGate, 2015 , DOI: $10.13140 / R G \cdot 2.1 .4461 .0642$.
38. Liu, R. Y.; Wang, J.; Sun, T.; Wang, M. J.; Wu, C. S.; Zou, H. Y.; Song, T.; Zhang, X. H.; Lee, S.-T.; Wang, Z. L.; Sun, B. Q.; Nano Lett. 2017, 17, 4240.

39. Payman, A.; Pierfederici, S.; Meibody-Tabar, F.; Energy Convers. Manage. 2008, 49, 1637.

40. Thounthong, P.; Chunkag, V.; Sethakul, P.; Sikkabut, S.; Pierfederici, S.; Davat, B.; J. Power Sources 2011, 196, 313.

41. Conway, B.; Pell, W.; J. Solid State Electrochem. 2003, 7, 637.

42. Li, J.; O'Shea, J.; Hou, X.; Chen, G. Z.; Chem. Commun. 2017, $53,10414$.

43. Wang, J. X.; Collionson, M. M.; J. Electroanal. Chem. 1998, 455, 127.

44. Peng, C.; Hu, D.; Chen, G. Z.; Chem. Commun. 2011, 47, 4105.

45. Xiao, W.; Hu, D.; Peng, C.; Chen, G. Z.; ACS Appl. Mater. Interfaces 2011, 3, 3120.

46. Bard, A. J.; Faulkner, L. R.; Electrochemical Methods: Fundamentals and Applications; Wiley: New York, 2001.

47. Zhang, S. W.; Peng, C.; Ng, K. C.; Chen, G. Z.; Electrochim. Acta 2010, 55, 7447.

48. Chae, J. H.; Chen, G. Z.; Electrochim. Acta 2012, 86, 248.

49. Demarconnay, L.; Raymundo-Pinero, E.; Beguin, F.; J. Power Sources 2011, 196, 580.

50. Ng, K. C.; Zhang, S.; Peng, C.; Chen, G. Z.; J. Electrochem. Soc. 2009, 156, A846.

51. Lin, T.; Chen, I.-W.; Liu, F.; Yang, C.; Xu, F.; Huang, F.; Science 2015, 350, 1508.

52. Padmanthan, N.; Shao, H.; Mcnulty, D.; O’Dwyer, C.; Razeeb, K. M.; J. Mater. Chem. A 2016, 4, 4820.

53. Zeiger, M.; Jackel, N.; Mochalin, V. N.; Presser, V.; J. Mater. Chem. A 2016, 4, 3172.

54. Cericola, D.; Novak, P.; Wokaun, A.; Kotz, R.; J. Power Sources 2011, 196, 10305.

55. Lee, J.; Kruner, B.; Tolosa, A.; Sathyamoorthi, S.; Kim, D.; Choudhury, S.; Seo, K.-H.; Presser, V.; Energy Environ. Sci. 2016, 9, 3392.

56. Roldan, S.; Granda, M.; Menendez, R.; Santamaria, R.; Blanco, C.; J. Phys. Chem. C 2011, 115, 17606.

57. Akinwolemiwa, B.; Chen, G. Z.; Curr. Top. Electrochem. 2017, 19, 48.

58. Lewandowski, A.; Olejniczak, A.; Galinski, M.; Stepniak, I.; J. Power Sources 2010, 195, 5814.

59. Wang, H.; Yoshio, M.; J. Power Sources 2008, 601.

60. Zhou, X.; Peng, C.; Chen, G. Z.; AIChe J. 2012, 58, 974.

61. Huang, Z.-H.; Song, Y.; Xu, X.-X.; Liu, X.-X.; ACS Appl. Mater. Interfaces 2015, 7, 25506.

62. Zhang, F.; Zhang, T. F.; Yang, X.; Zhang, L.; Leng, K.; Huang, Y.; Chen, Y. S.; Energy Environ. Sci. 2013, 6, 1623.

63. Klankowski, S. A.; Pandey, G. P.; Malek, G. A.; Wu, J.; Rojeski, R. A.; Li, J.; Electrochim. Acta 2015, 178, 797. 
64. https://cdn.shopify.com/s/files/1/0674/3651/files/panasonicncr18650-ga-spec-sheet.pdf, accessed on December 2, 2017.

65. Zhou, X. H.; Chen, G. Z.; J. Electrochem. 2012, 18, 548.
66. Hwang, J. Y.; El-Kady, M. F.; Li, M.; Lin, C.-W.; Kowal, M.; Han, X.; Kaner, R. B.; Nanotoday 2017, 15, 15. 67. Huang, C.; Grant, P. S.; Sci. Reports 2013, 3, 2393.

Submitted: October 31, 2017 Published online: January 23, 2018 